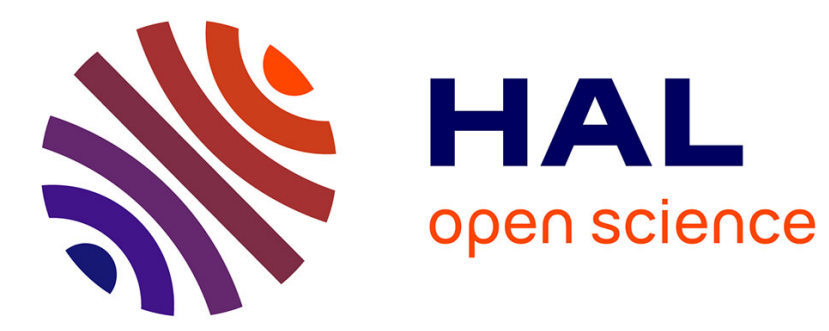

\title{
In-Vivo Soft Tissues Mechanical Characterization: Volume-Based Aspiration Method Validated on Silicones
}

Seyed Ali A Elahi, Nathanaël Connesson, Grégory Chagnon, Yohan Payan

\section{To cite this version:}

Seyed Ali A Elahi, Nathanaël Connesson, Grégory Chagnon, Yohan Payan. In-Vivo Soft Tissues Mechanical Characterization: Volume-Based Aspiration Method Validated on Silicones. Experimental Mechanics, 2019, 59, pp.251-261. 10.1007/s11340-018-00440-9 . hal-01974859

\section{HAL Id: hal-01974859 https://hal.science/hal-01974859}

Submitted on 30 Jan 2019

HAL is a multi-disciplinary open access archive for the deposit and dissemination of scientific research documents, whether they are published or not. The documents may come from teaching and research institutions in France or abroad, or from public or private research centers.
L'archive ouverte pluridisciplinaire HAL, est destinée au dépôt et à la diffusion de documents scientifiques de niveau recherche, publiés ou non, émanant des établissements d'enseignement et de recherche français ou étrangers, des laboratoires publics ou privés. 


\title{
In-vivo soft tissues mechanical characterization: volume-based aspiration method validated on silicones
}

\author{
S.A. Elahi · N. Connesson • \\ G. Chagnon · Y. Payan
}

Abstract Simulating the deformations of soft tissues has gained importance in recent years due to the development of $3 \mathrm{D}$ patient-specific biomechanical models in the context of Computer Assisted Medical Interventions. To design such models, the mechanical behavior of each soft tissue has to be characterized in-vivo. In this paper, a volume-based aspiration method for in-vivo mechanical characterization of soft tissues was validated on synthetic materials. For this purpose, two silicones with slightly different stiffnesses were made. Samples were characterized using (1) aspiration, and, as references, two classical tests such as (2) uniaxial and (3) equibiaxial extension tests.

Performing a Finite Element (FE) inverse identification on the experimental results provided Young's moduli similar to classical tests with about 7\% maximum overestimation for the two silicones. This highlighted a significant improvement of the measurement method accuracy compared to the literature (about $30 \%$ relative overestimation).

Corresponding Author

TIMC-IMAG Laboratory, UMR CNRS 5525, Grenoble Alpes University, Pavillon Taillefer, Faculty of Medicine, Domaine de la Merci, 38706 La Tronche cedex, France.

E-mail: nathanael.connesson@univ-grenoble-alpes.fr 
Eventually, the aspiration method ability to discriminate the two silicones was also tested and proven to be similar to classical characterization tests. Based on the presented results, relative mechanical behavior mapping of soft tissues (organ or skin) is possible without requiring an inverse characterization procedure.

Keywords Suction/Aspiration Method - Soft Tissues Characterizations · In-Vivo Measurement $\cdot$ Silicone $\cdot$ Experimental Mechanics.

\section{Introduction}

The constitutive laws that characterize the mechanical properties of human soft tissues are required for modeling and simulating tissues and organs' re-

sponses to external mechanical stresses [1-4]. The mechanical behavior of living tissues varies between in-vivo and ex-vivo conditions [5]. It is thus of first interest to characterize the tissue properties in-vivo and in-situ for applications such as surgical training, tissue replacement engineering, trauma research, etc..

To perform intra-operative measurements on human, the procedure must be non-traumatic and operated under sterile conditions. It also has to comply with space and time limitations in the operating room. Considering these constraints, several devices were developed in the literature based on various measurement methods [6-12]. Among all these methods, the aspiration technique is among the easiest to use and provides a method to control the applied experimental boundary conditions [13].

The aspiration method consists in putting a chamber with an aperture in contact with the investigated tissue and in decreasing the pressure inside the chamber. Due to the pressure difference, the portion of the tissue under the aperture is partially aspirated. For a given pressure difference, authors usually propose to measure the aspirated tissue height using different methods such as 
ultrasound [11,14], mechanical stops [15] or cameras, associated with mirrors or prisms [16-24]. These measurement methods yet meet different challenges:

- Ultrasound imaging requires the use of an ultrasound machine and a large amount of coupling liquid interfacing the probe with the tissue [11].

- The method based on a mechanical stop retrieves only the pressure at which the material reaches the stop.

- The methods using optical measurements have limitations concerning sterilization. In addition, the use of cameras and mirrors or prisms requires accurate relative positioning, which leads to devices that can be large, complex and expensive $[16,21]$.

These limitations motivated the authors to design a new disposable system for in-vivo mechanical characterization of soft tissues based on volume measurement [25]. In this novel method, apex height measurement was replaced by measurement of the aspirated tissue volume. Such a change in the method enabled the elimination of camera, mirror, prism, and all the electronic parts from the system head that was basically reduced to a simple tube with an aperture. The system head is thus disposable, highly customizable (aperture size, shape, material, and etc.) and is able to meet any required severe sterilization process. The proposed system is probably among the simplest, lightest and most inexpensive that one could achieve.

This volume-based method measures the negative pressure in the chamber and the associated volume of the soft tissue aspirated through the device's aperture [25]: the pressure is thus known as a function of the volume. The material properties of the tissue can be identified with these experimental data using an inverse updated Finite Element (FE) method [17].

The aim of this paper is to validate the volume-based aspiration method on synthetic materials. For this purpose, Young's modulus value of each material 
will be estimated using an inverse updated FE method and a Gent model. In particular, the discrimination ability of the method will be studied on two silicone samples, one being softer than the other.

\section{Experiments}

\subsection{Silicone samples}

According to the literature, several synthetic materials have mechanical properties within the same range of human soft tissues $[13,22,28]$. RTV-EC00 silicone, obtained by mixing two components (base and catalyst), was chosen due to its ability to generate samples with a very low stiffness (equivalent Young's modulus of the order of some $\mathrm{kPa}$ ). After removing any air bubble from the mixture using a vacuum chamber, samples were hardened for two weeks at room temperature. For RTV-EC00 silicone, changing the ratio of base and catalyst impacts the silicone stiffness. Two soft silicones were thus generated, using the ratios:

- Silicone\#1: $40 \%$ base, $60 \%$ catalyst.

- Silicone\#2: $45 \%$ base, $55 \%$ catalyst.

For each silicone, three types of samples were created using two different molds:

- Aspiration test: cylindrical bulk sample (110 $\mathrm{mm}$ diameter, $50 \mathrm{~mm}$ height)

- Tensile and bulge test: $2 \mathrm{~mm}$ thick membrane cut either into a $50 \mathrm{~mm}$ diameter disk or $4 \mathrm{~mm} \times 100 \mathrm{~mm}$ strips.

For each silicone, all samples were made on the same day from the same mixture to ensure identical mechanical properties. 


\subsection{Aspiration tests}

The aspiration system and volume-based method will be briefly presented in this section. Details can be found in [25]. An aspiration head was applied on a soft material (Fig. 1) while a negative pressure aspirates part of this material through a circular aperture of $9.7 \mathrm{~mm}$ diameter. A programmable syringe pump coupled with a syringe (Sy1 in Fig. 1a) was used to reduce the pressure inside the system. During the test, the pressure variation $P$ was measured using a digital manometer with a precision of \pm 0.004 mbar. The corresponding aspirated volume $V^{\text {total }}$ was measured by the syringe pump given the piston translation with a resolution of $\pm 0.002 \mathrm{ml}$.

The measured volume $V^{\text {total }}(P)$ contains information on both the aspirated tissue volume inside the chamber $V_{\text {tissue }}(P)$ and the volume changes in the device $V_{\text {system }}(P)$ (air expansion, the elasticity of the connections, tubes, syringe, etc.). The changes in the system volume $V_{\text {system }}$ were experimentally assessed during a second step by testing an undeformable material (stiff material in comparison to the system): in this experimental configuration the aspirated tissue volume $V_{\text {tissue }}$ remains zero and the system volume $V_{\text {system }}$ compressibility can be directly measured. Such an experiment provided the required data to evaluate a calibration curve $V_{\text {system }}(P)$. The aspirated tissue volume $V_{\text {tissue }}^{\text {exp }}$ can thus naturally be estimated by:

$$
V_{\text {tissue }}^{\text {exp }}(P)=V^{\text {total }}(P)-V_{\text {system }}(P)
$$

As experimentally demonstrated in [25], decreasing the Syringe Diameter of Sy1 (SD in Fig. 1a) improves the measurement precision and repeatability: Sy1 is here a $1 \mathrm{ml}$ syringe with a diameter of $4.7 \mathrm{~mm}$. However, using a small syringe also limits the aspirated volume range and thus the maximal aspirated tissue volume $V_{\text {tissue }}$. In order to solve this problem, a valve and 
an additional $1 \mathrm{ml}$ syringe with a diameter of $4.7 \mathrm{~mm}$ (Sy2 in Fig. 1a) were added to the system. Before starting the syringe pump, an initial volume was withdrawn from the system using Sy2, while applying a vertical load to the aspiration probe to limit possible leakage. The applied vertical load was then removed and the withdrawn volume was manually adjusted to reach $P_{0}$. The valve was then closed and the associated initial volume $V_{0}^{\text {total }}$ was read directly on the syringe Sy2. It should be mentioned that this volume $V_{0}^{\text {total }}$ shall be overestimated due to initial leakage. If no leakage occurs and given the nominal volume of Sy2 $(1 \mathrm{ml}), V_{0}^{\text {total }}$ is estimated to be measured at $\pm 0.01 \mathrm{ml}$, which is the smallest division of syringe Sy2 scale.

Using Eq. 1, the starting point $\left(V_{0(\text { tissue })}^{\text {exp }}, P_{0}\right)$ was computed and considered as the initial situation. Impact of potential errors on the experimental measurement of $V_{0(\text { tissue })}^{\text {exp }}$ will be discussed in section 5.1.

The volume loading path, defined with four steps (air aspiration/injection, see Fig. 2a), was then applied using Sy1 in both tests, either with the silicone or the undeformable surface. As all the pressures dealt with are negative compared to atmospheric pressure, only the absolute values will be discussed. An example of pressure results is plotted versus time in Fig. 2b. The pressurevolume curves of the tests were extracted from the data (Fig. 2c, red and blue curves) and the tissue pressure-volume curve was computed using Eq. 1 (Fig. 2c, green curves).

In this study, the initial pressure $P_{0}$ was set to be 50 mbar (the maximum applied pressure during this work is of 168 mbar $)$. Total volume changes, controlled using the syringe pump, were applied with the rate of $0.4 \mathrm{ml} / \mathrm{min}$, which was experimentally checked to be small enough to provide the quasistatic mechanical behavior for the tested material. This was ensured by repeating the various tests at different deformation rates and choosing a slow enough rate. 

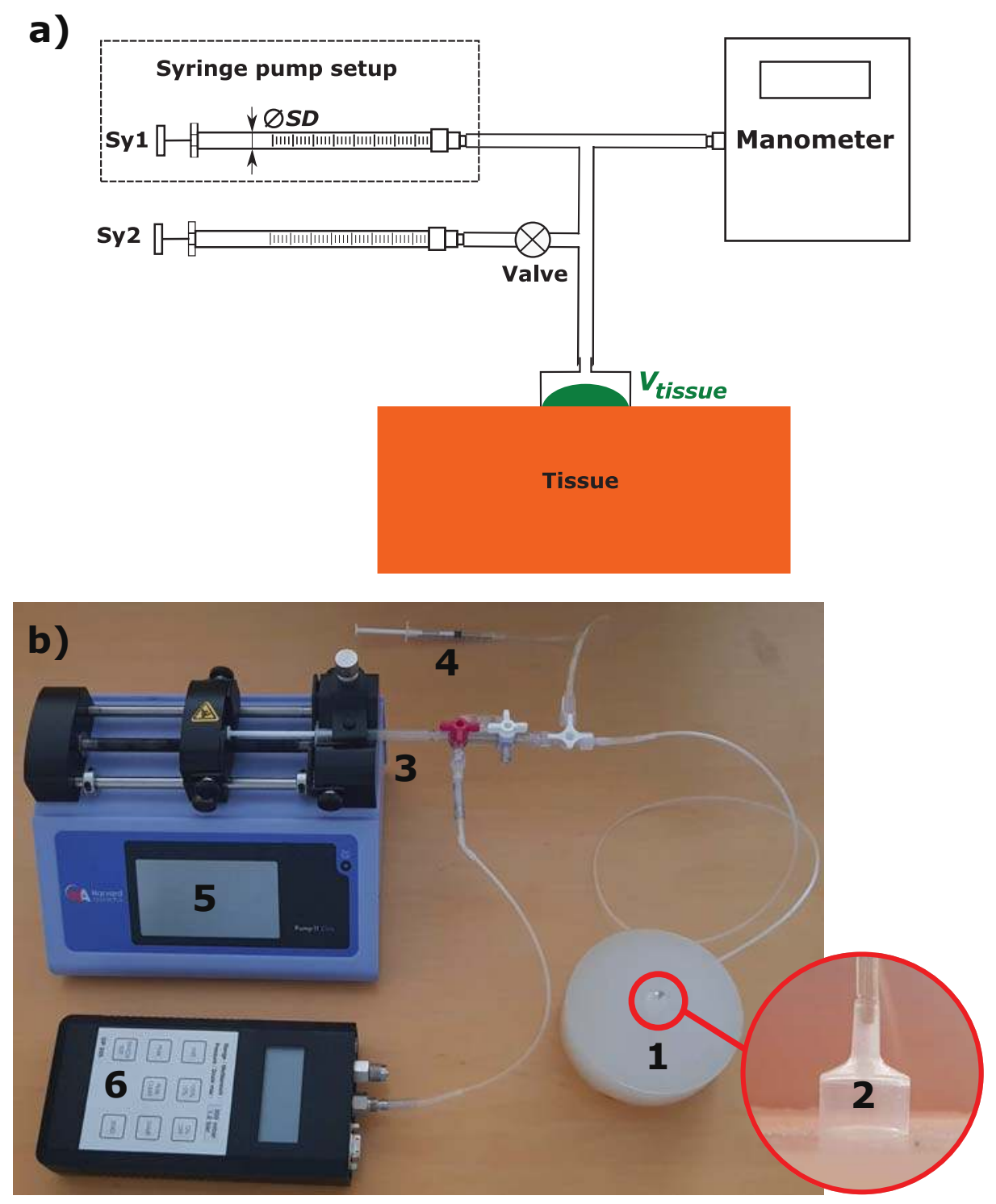

Fig. 1 Volume-based aspiration setup: a) schematic and b) photograph of the setup: (1) silicone sample, (2) aspiration probe, (3) Sy1, (4) Sy2, (5) syringe pump and (6) manometer.

In order to check the reproducibility of the results, the aspiration tests on each silicone were repeated nine times in the same condition. For each set of the nine tests, the STandard Deviation (STD) of the volume measurements $V_{\text {tissue }}$ were calculated and used as a parameter to assess the measurement precision and reproducibility. 
a)

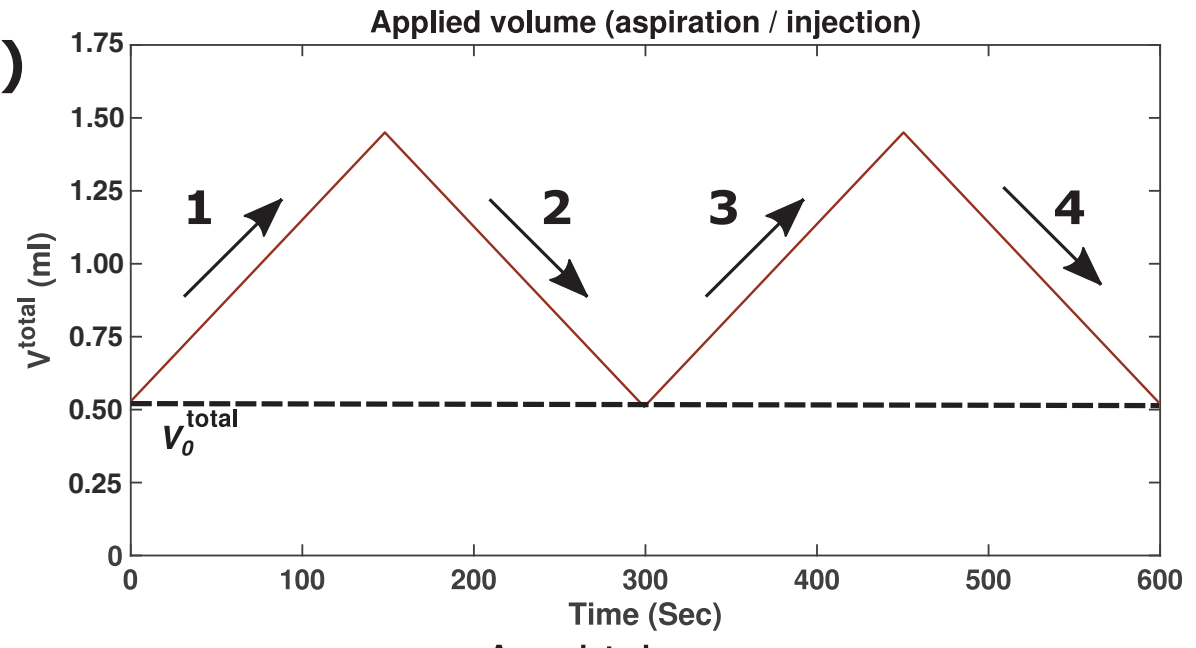

b)

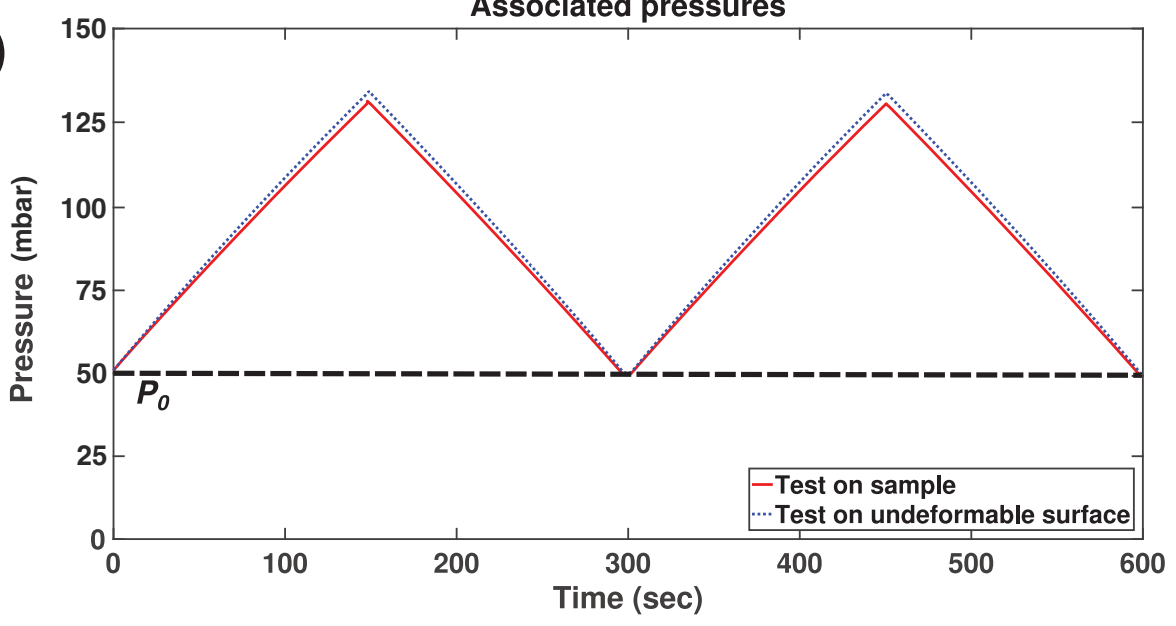

c)

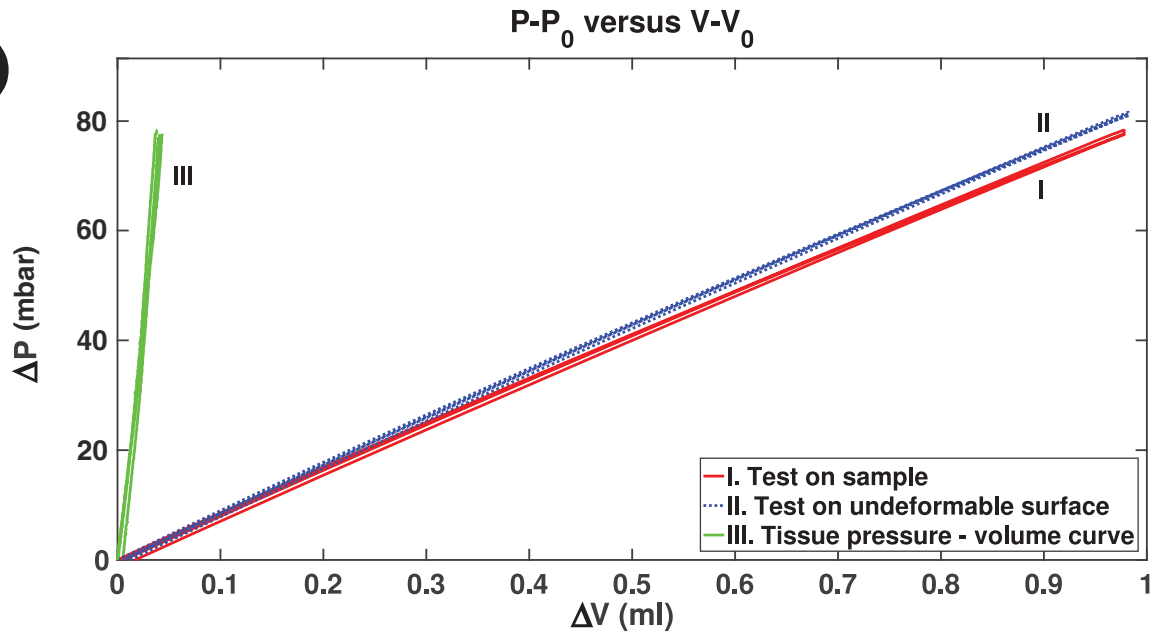

Fig. 2 Methodology (example on Silicone\#1): a) applied volume loading path, b) associated negative pressures of the test on the sample (red) and on the undeformable surface (blue) and c) resulting pressure-volume curves (red and blue) and extracted tissue behavior (green).

\subsection{Classical characterization tests}

Two classical characterization tests, namely uniaxial tensile test (Fig. 3a) and equibiaxial tensile test generated at the top of a bulge test (Fig. 3b), were 
used to identify the reference stress-strain behaviors of the silicones and their associated mechanical parameters. These results will then be compared with the volume-based aspiration method measurements.

\subsubsection{Uniaxial tensile test}

For the uniaxial tensile measurements, an MTS machine with a load cell of $25 N$ was used (MTS Criterion, Model 41). For each silicone material, 20 rectangular specimens were made. Five groups, each contained 4 specimens, were tested at different engineering extensional strain levels $\left(\epsilon_{x x(\max )}=20 \%\right.$, $30 \%, 50 \%, 80 \%$ and 100\%) (Fig. 3a). In order to see any possible hysteresis and load history impact on the material behavior, each sample was tested during 5 loading-unloading cycles.

\subsubsection{Bulge test}

A bulge test was also conducted. A circular sample of $2 \mathrm{~mm}$ thickness was clamped between two flanges (Fig. 3). A syringe connected to the bottom of the circumferential clamp was used to inject a liquid under the disk to perform the bulge test. The membrane was thus inflated using the syringe pump while measuring the internal pressure with a manometer.

The 3D membrane displacement was tracked using Stereo Digital Image Correlation (SDIC, Figs. 3b and 3c). The upper surface of the silicone sample was coated with a stochastic paint pattern made of small black speckles to comply with the SDIC requirement and to extract strain field maps over the membrane. Due to the transparency of the used materials, the system was filled with a white color liquid such as milk to provide a proper contrast.

The axial-symmetry of the experimental configuration induces the equibiaxiality of the stress and strain state at the top of the inflated membrane 
(point M, Fig. 3c) [26]. Given the thickness dimension is $1 / 25$ th of the membrane diameter, the in-plane stresses were assumed to be uniform along the thickness dimension. The curvature of the inflated sample was also assumed to be the same along all directions at the disk center due to the system axialsymmetry and the materials isotropy and homogeneity. A region of $3 \mathrm{~mm}^{2}$ at the sample pole, around point M, was considered for the analysis. In-plane components of First Piola-Kirchhoff stress $\sigma_{x x(B u l g e)}=\sigma_{y y(B u l g e)}$ at point $\mathrm{M}$ can thus be calculated using the equation [26]:

$$
\sigma_{x x(\text { Bulge })}=\sigma_{y y(\text { Bulge })}=\frac{p r}{2 e_{0}} \lambda_{(B u l g e)} ; \quad \sigma_{z z(B u l g e)}=0
$$

where $e_{0}$ is the initial thickness of the specimen, $r$ the local curvature radius, $\lambda_{(B u l g e)}=\lambda_{x x}=\lambda_{y y}$ the principal stretch and $p$ the pressure recorded during the test (Fig. 3d). The details about the calculation of the stress from the SDIC measurement can be found in [27].

The bulge test was performed on 4 different specimens for each silicone. In order to study any possible hysteresis and load history impact on the behavior of the materials, each sample was tested during 5 inflating-deflating cycles up to a max strain of $70 \%$. The average responses of the 4 different specimens were then calculated.

\section{Modeling and inverse characterization}

In order to perform the inverse characterization of the materials using aspiration tests, a material model was selected. This model was also used to identify the materials mechanical parameters using the classical characterization tests. In the following sections, the used material model, FE modeling of the aspiration tests and the materials parameters identification methods using both classical and aspiration tests will be presented. 

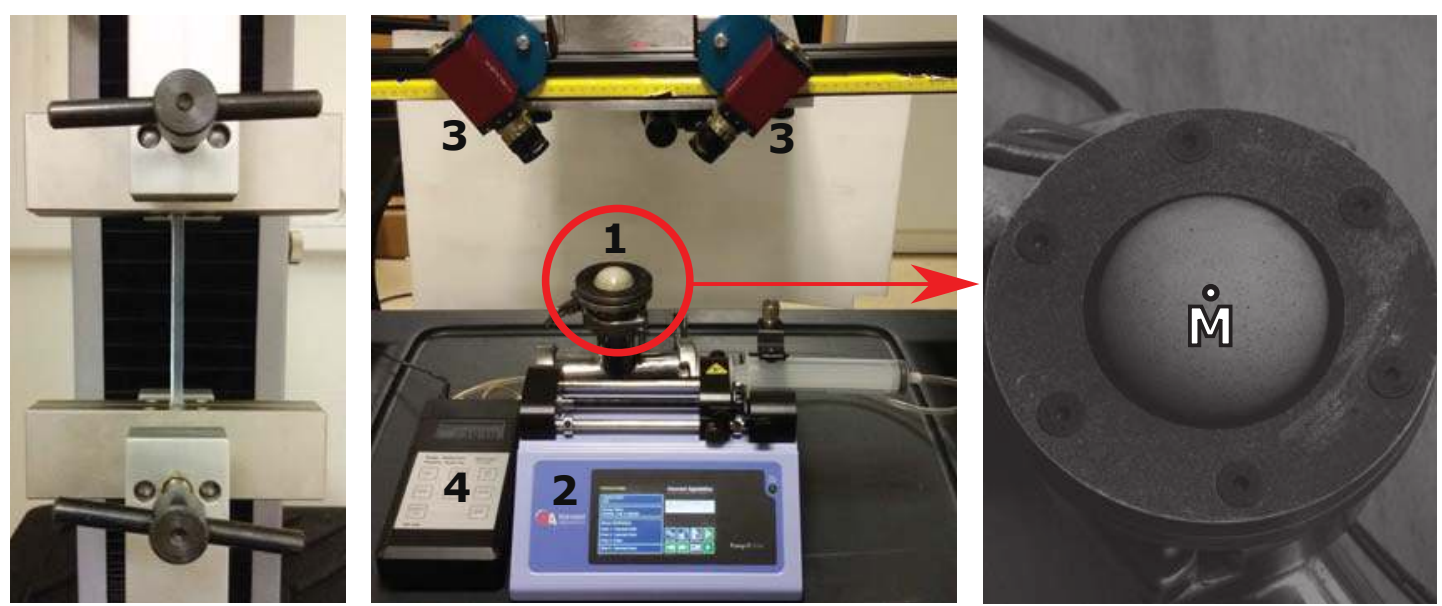

\section{d)}

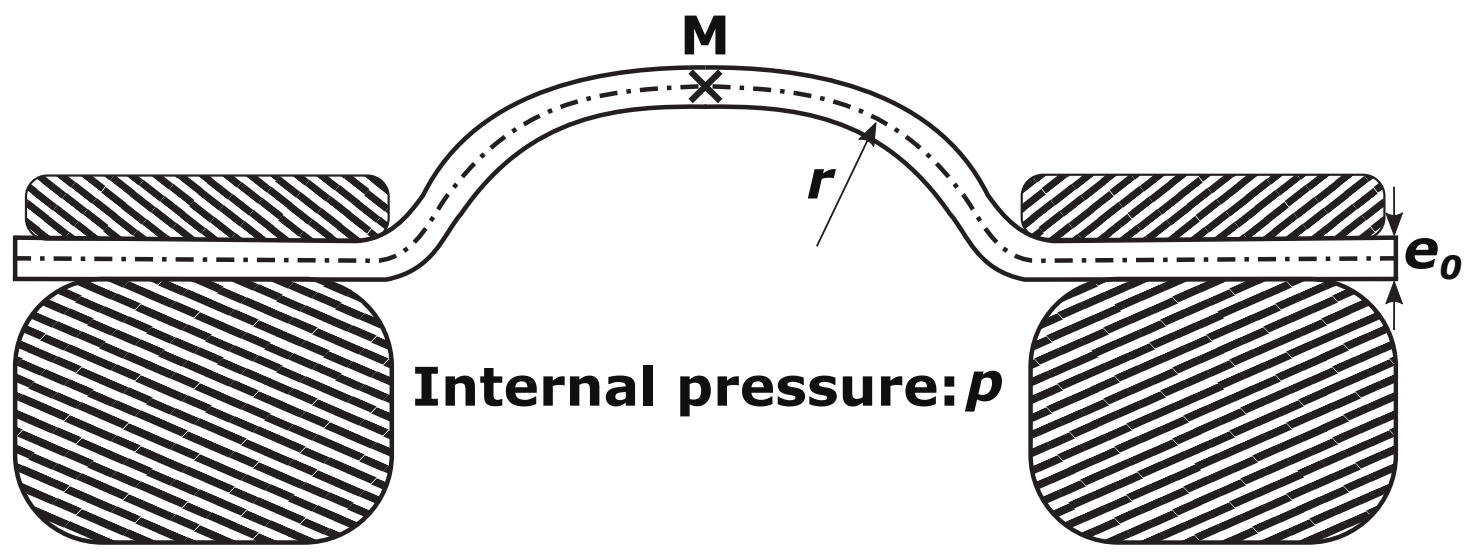

Fig. 3 a) Tensile test setup, b) Bulge test setup: (1) Bulge membrane and circular clamp, (2) syringe and syringe pump, (3) cameras, (4) manometer, c) close-up view of the inflated silicone sample and localization of equibiaxial loading (point $\mathrm{M}$ ) and d) schematic of the bulge test setup.

\subsection{Gent material model}

The hyperelastic model proposed by Gent [29] was used to model the silicone rubbers [30]. The strain energy function of the Gent model $\left(W_{G}\right)$ is given by:

$$
W_{G}=-\frac{E J_{m}}{6} \ln \left(1-\frac{I_{1}-3}{J_{m}}\right)
$$

where $E$ and $J_{m}$ are the two material parameters and $I_{1}$ is the first Cauchy Green strain invariant. $J_{m}$ represents the maximum value of $\left(I_{1}-3\right)$ that can be undergone by the material. The Gent model was used to identify the materials 
parameters either using FE inverse method and the aspiration tests results or using the classical characterization results.

3.2 FE modeling of the aspiration tests

A FE simulation of the aspiration tests was performed (ANSYS software) in order to identify the materials parameters. The tests were modeled in 2D with axisymmetry (Fig. 4). As the silicone cylinder diameter and height were respectively about 11 and 5 times larger than the aperture diameter (section 2.1), boundary conditions on the bottom and the outer sides of the tissue structure do not have any effect on the simulations results. The bottom layer of the nodes was fixed for horizontal and vertical displacements and the outer side of the tissue was allowed to move freely. The sample was meshed with 5800 Quadrilateral 8-node (Q8) elements. The experimental contact properties between the aspiration aperture and the material are unknown. To study the sensitivity of simulation results on these properties, the contact was modeled with two assumptions: (1) a frictionless contact (friction coefficient based on the Coulomb's Law $\mu=0$ ) and (2) a contact with a friction coefficient of $\mu=1$. The displacement of the tissue surface inside the aperture was used to compute the aspirated volume at each pressure step.

3.3 Material parameters identification

\subsubsection{Reference material parameters identification on classical tests results}

To identify the Gent model parameters using classical tests, the Fist PiolaKirchhoff stress-stretch relations were calculated based on Eq. 3 for uniaxial and equibiaxial extensions, respectively as: 


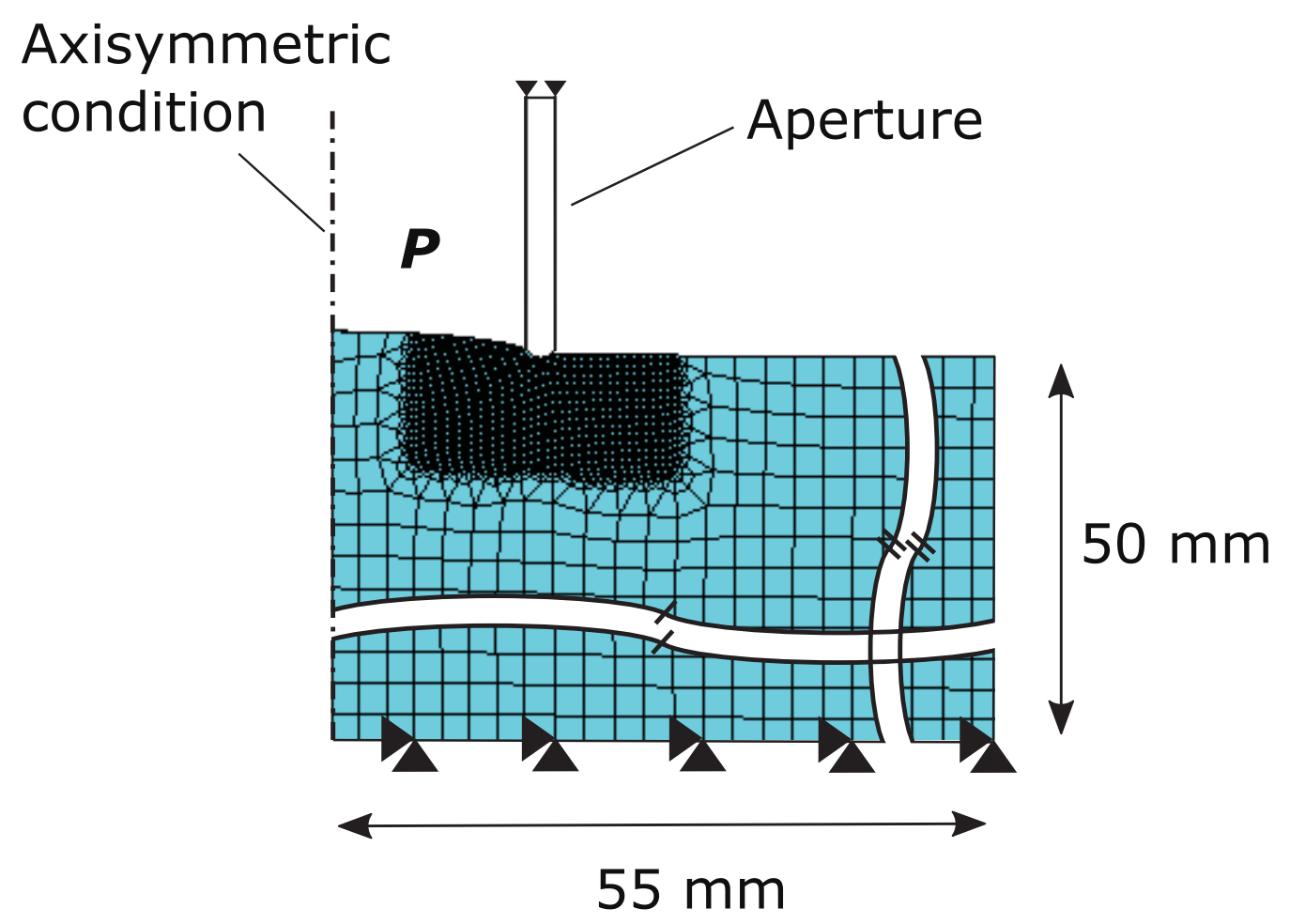

Fig. 4 Schematic of the FE model and boundary conditions of the aspiration experiment in the deformed configuration.

$$
\sigma_{x x(u n i)}=\left(\lambda_{(u n i)}^{2}-\frac{1}{\lambda_{(u n i)}}\right)\left[\frac{E J_{m} / 3}{\left(J_{m}+3\right) \lambda_{(u n i)}-\lambda_{(u n i)}^{3}-2}\right]
$$

and

$$
\sigma_{x x(\text { equi })}=\sigma_{y y(\text { equi })}=\left(\lambda_{(\text {equi })}^{5}-\frac{1}{\lambda_{(\text {equi })}}\right)\left[\frac{E J_{m} / 3}{\left(J_{m}+3\right) \lambda_{(\text {equi })}^{4}-2 \lambda_{(\text {equi })}^{6}-1}\right]
$$

where $\sigma_{x x(u n i)}$ and $\sigma_{x x(\text { equi) }}$ are stresses and $\lambda_{(u n i)}$ and $\lambda_{(\text {equi) }}$ are stretches in uniaxial and equibiaxial extensions, respectively. Details about the calculation of the stresses using the strain energy function can be found in [31].

The reference model parameters for each material were estimated by minimizing the least square function $S$, combining both uniaxial tensile and bulge results: 


$$
S=\frac{\sum_{j=1}^{J}\left(\left(\sigma_{x x(\text { uni }) j}-\sigma_{x x(\text { Tensile }) j}\right)^{2}\right)}{J}+\frac{\sum_{k=1}^{K}\left(\left(\sigma_{x x(\text { equi }) k}-\sigma_{x x(\text { Bulge }) k}\right)^{2}\right)}{K}
$$

where:

- $\sigma_{x x(u n i)}$ and $\sigma_{x x(e q u i)}$ are described by Eqs. 4 and 5,

- $\sigma_{x x \text { (Tensile) }}$ and $\sigma_{x x(B u l g e)}$ are stresses from the tensile and the bulge tests, respectively,

- $j$ and $k$ are the deformation steps indices in the tensile and the bulge tests, respectively,

- $J$ and $K$ are the total numbers of deformation steps in the tensile and the bulge tests, respectively.

\subsubsection{Inverse material parameters identification on aspiration tests results}

To identify the model parameters (Eq. 3) using aspiration tests, an optimization process was adapted from Weickenmeier et al. [24]. The optimization scheme was extended to minimize the least square function $\phi$ representing the fitting quality of the pressure-volume curves obtained from the FE simulation $\left(V_{\text {tissue }}^{\text {sim }}\right)$ and the experimental aspiration test $\left(V_{\text {tissue }}^{\text {exp }}\right)$ :

$$
\phi=\sum_{i=1}^{I}\left[V_{\text {tissue }}^{\text {sim }}\left(P_{i}\right)-\left(V_{0(\text { tissue })}+V_{\text {tissue }}^{\text {exp }}\left(P_{i}\right)\right)\right]^{2}
$$

where $P_{i}$ presents the measured pressure in the $i$ th step, $I$ is the number of points retrieved during the test and $V_{\text {tissue }}^{\text {exp }}\left(P_{i}\right)$ is the experimental data. The unknowns to identify are the material parameters $E$ and $J_{m}$ and the initial aspirated volume $V_{0 \text { (tissue) }}$ that could be affected by leakage.

A schematic of the optimization process is presented in Fig. 5, where $E_{0}$, $J_{m 0}$ and $V_{0(\text { tissue })}^{\text {exp }}$ are initial guessed values, $E_{i}, J_{m i}$, and $V_{0 i(t i s s u e)}$ are the 
iteratively adapted parameters, and $E_{f}, J_{m f}$, and $V_{0 f(t i s s u e)}$ are the final results of the optimization process. The material parameters and the initial aspirated volume in each iteration were guessed using a Nelder-Mead simplex algorithm [32] (fminsearch procedure in MATLAB).

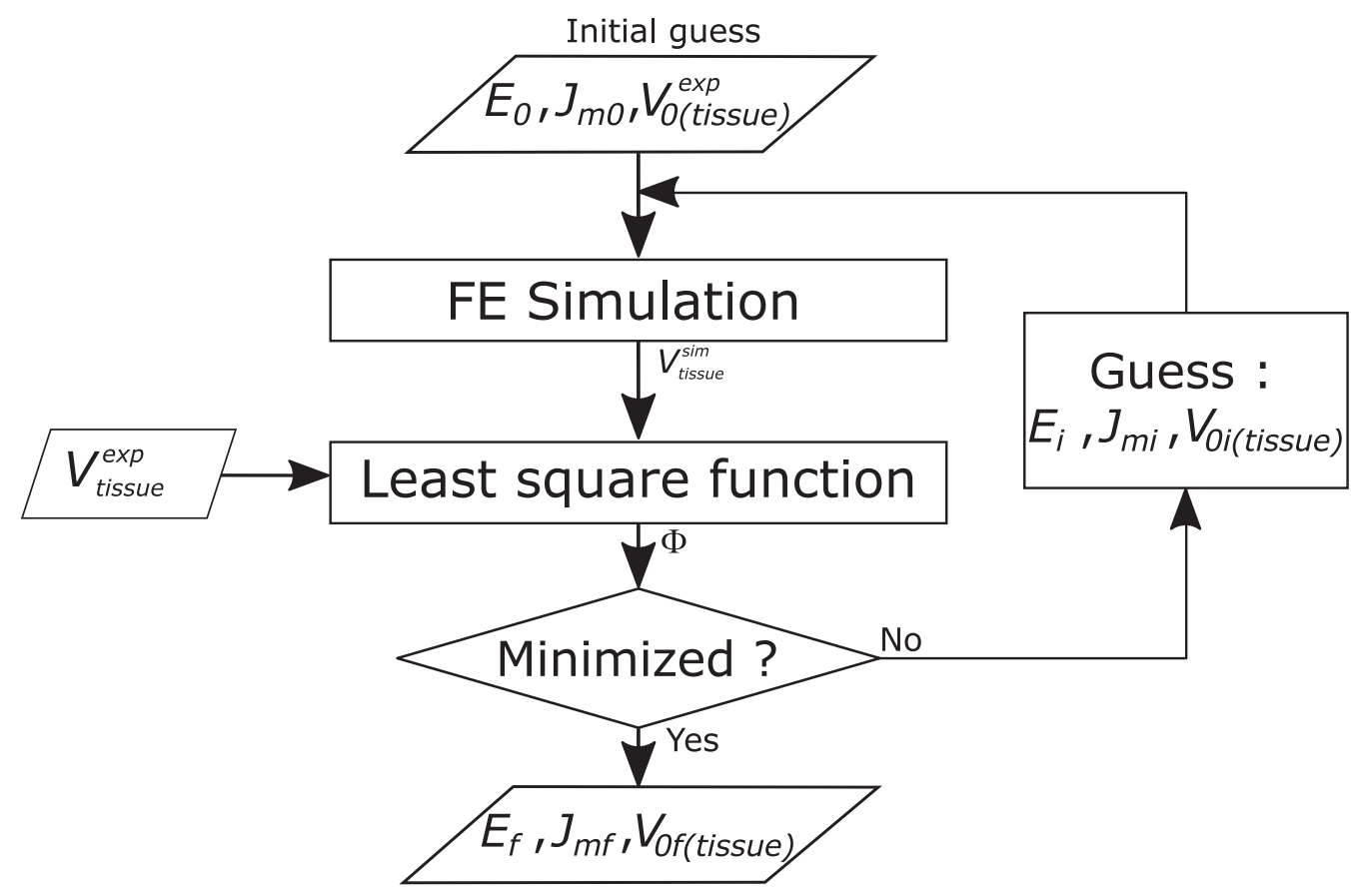

Fig. 5 Schematic representation of the optimization process for the inverse characterization of the model parameters.

\section{Results}

\subsection{Aspiration results}

Results of the volume-based aspiration measurements (loading steps 1 and 3 in Fig. 2a) on Silicones\#1 and \#2 are presented in Fig. 6: for each material, average and STD of pressure-volume $\left(P\right.$ versus $\left.V_{\text {tissue }}^{\text {exp }}\right)$ curves of the nine aspiration tests are plotted. The STD of volume measurements according to the average values for Silicones\#1 and \#2 are $2.63 \%$ and $2.53 \%$, respectively. This highlights the high reproducibility of the aspiration measurements on 
both materials and also the precision of the measurements. Moreover, the results presented in Fig. 6 validate the ability of the volume-based aspiration method to clearly discriminate the two slightly different materials properly: given the measurement precision, aspiration behaviors contrast of more than $2 \times \mathrm{STD}=5 \%$ can be identified.

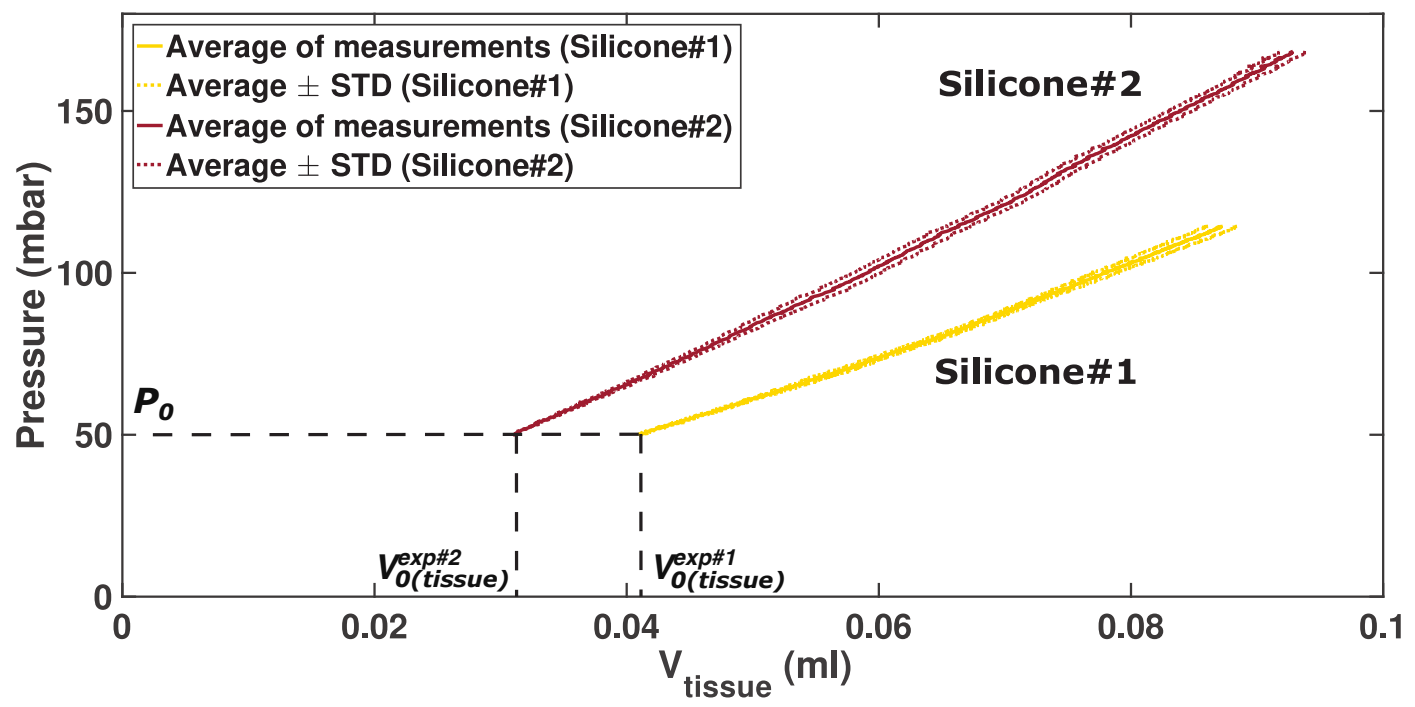

Fig. 6 Averages and associated STD of pressure-volume curves (loading steps 1 and 3 in Fig. 2a) of nine aspiration measurements for Silicones\#1 and \#2.

\subsection{Classical characterization results}

The averaged stress-strain curves over 4 specimens of the uniaxial tensile tests on Silicones\#1 and \#2 with increasing strain levels $\left(\epsilon_{x x(\max )}=20 \%, 30 \%\right.$, $50 \%, 80 \%$ and 100\%) are presented in Fig. 7a. For each strain level, the curve of the five-cycle (load-unload) tensile tests is plotted. These results indicate that both materials present no hysteresis nor stress softening. Moreover, the superposition of the stress-strain curves with different strain levels and different specimens confirms the test reproducibility and accuracy for both silicones. 

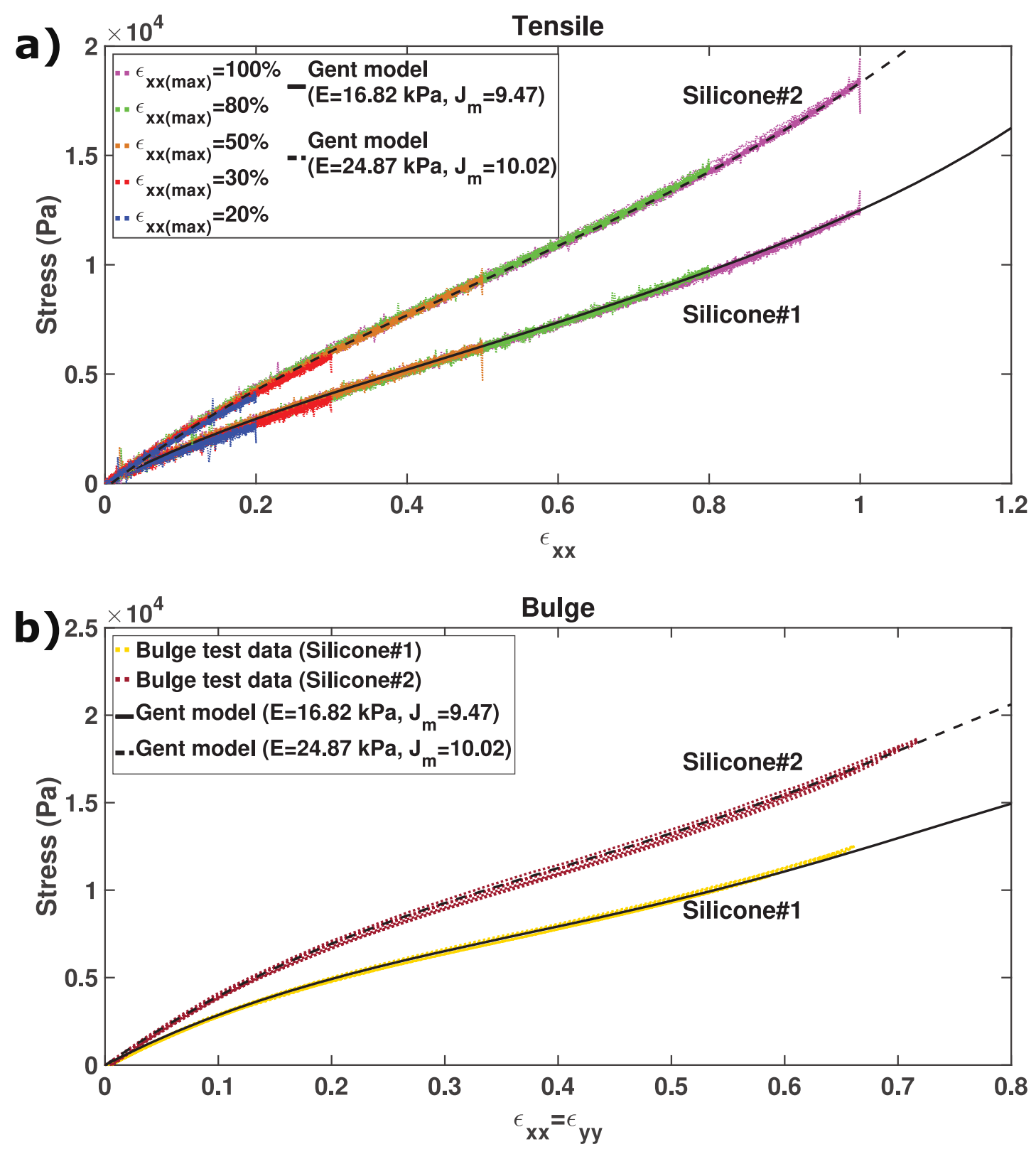

Fig. 7 Stress-strain results and fitted Gent model using Eq. 6 for Silicones\#1 and \#2 (five loading-unloading cycles for each): a) tensile tests with increasing strain levels and b) bulge tests.

The averaged stress-strain results over 4 specimens of the five-cycle (loadunload) equibiaxial bulge tests on Silicones\#1 and \#2 are plotted in Fig. 7b. As previously, no hysteresis behavior and no stress softening can be observed in these results and behavior differences between samples during the five cycles on each material are indiscernible as was expected for unfilled silicone rubbers [33]. 
Table 1 Gent model parameters of the silicone materials obtained from classical and inverse characterizations with friction coefficients of $\mu=0$ and 1 . Relative errors were calculated in comparison with the reference parameters.

\begin{tabular}{lllll}
\hline \multirow{2}{*}{ Material } & $\begin{array}{l}\text { Material } \\
\text { Constants }\end{array}$ & $\begin{array}{l}\text { Classical } \\
\text { characterization }\end{array}$ & $\begin{array}{l}\text { Inverse } \\
\text { characterization } \\
\text { for } \mu=[0,1]\end{array}$ & $\begin{array}{l}\text { Comparison } \\
\text { error }(\%) \\
\text { for } \mu=[0,1]\end{array}$ \\
\hline \multirow{2}{*}{ Silicone\#1 } & $E$ & $16.82 \mathrm{kPa}$ & {$[18.30,17.76] \mathrm{kPa}$} & {$[8.8,5.6]$} \\
\cline { 2 - 5 } & $J_{m}$ & 9.47 & {$[9.89,9.65]$} & {$[4.4,1.9]$} \\
\hline \multirow{2}{*}{ Silicone\#2 2} & $E$ & $24.87 \mathrm{kPa}$ & {$[26.51,25.89] \mathrm{kPa}$} & {$[6.6,4.1]$} \\
\cline { 2 - 5 } & $J_{m}$ & 10.02 & {$[10.16,10.11]$} & {$[1.4,0.9]$} \\
\hline
\end{tabular}

Gent model curves for uniaxial and equibiaxial extensions (Eqs. 4 and 5) were respectively fitted to the tensile and bulge tests data of each silicone material (Figs. 7a and 7b). Both fittings for each silicone were performed simultaneously by minimizing the cost function $S$ (Eq. 6) to estimate the best reference parameters $\left(E\right.$ and $\left.J_{m}\right)$ as provided in Table 1. Since the experimental results of the tensile tests with different levels of strains overlapped (Fig. 7a), the Gent model was only fitted to the results of the tests with $\epsilon_{x x(\max )}=100 \%$ strain level.

\subsection{Inverse characterization results}

The identified material parameters $E_{f}$ and $J_{m f}$ obtained after the minimization of the cost function $\phi$ (section 3.3.2) for both contact conditions (frictionless and with friction coefficient $\mu=1$ ) and their errors in comparison to classical characterization results are reported in Table 1 . Table 2 compares the identified initial aspirated volumes $V_{0 f(t i s s u e)}$ and their corresponding values obtained from the experiments $V_{0(t i s s u e)}^{e x p}$. Values of the cost function $\phi$ for different materials and contact conditions are also reported in Table 2.

Comparison of the material model parameters obtained from the inverse and the classical characterizations shows a slight overestimation (about 7\%) of the inverse characterization for both silicones (Table 1). 
Table 2 Initial aspirated volume measured (Column 1) or identified (Column 2) using the optimization procedure with friction coefficients of $\mu=0$ and 1. Column 3: relative differences between measured and identified volumes. Column 4: final value of cost function $\phi$ after minimization (Eq. 7).

\begin{tabular}{|c|c|c|c|c|}
\hline Material & $\begin{array}{l}\text { Experimental } \\
\text { initial volume } \\
V_{0}^{e x p}(m l)\end{array}$ & $\begin{array}{l}\text { Identified } \\
\text { initial volume } \\
V_{0 f(\text { tissue })(m l)} \\
\mu=[0,1]\end{array}$ & $\begin{array}{l}\text { Mismatch } \\
(\%) \\
\mu=[0,1]\end{array}$ & $\begin{array}{l}\phi \text { value } \\
\left(m l^{2}\right) \\
\mu=[0,1]\end{array}$ \\
\hline Silicone\#1 & 0.04 & {$[0.0424,0.0410]$} & {$[6.0,2.5]$} & {$[4.8,6.3] \times 10^{-} 3$} \\
\hline Silicone\#2 & 0.03 & {$[0.0314,0.0304]$} & {$[4.7,1.3]$} & {$[3.2,6.1] \times 10^{-} 3$} \\
\hline
\end{tabular}

\section{Discussion}

\subsection{Inverse identification results}

The direct comparison of the numerical curves and the experimental aspiration curves are presented in Fig. 8. The materials parameters obtained from both the classical measurements and inverse identifications were used for the $\mathrm{FE}$ simulations (Table 1). The plotted curves of FE simulations with the identified materials parameters in Fig. 8 validate the identifications and adequacy of the chosen constitutive model equation (Eq. 3).

A difference lower than $6 \%$ between experimental and identified initial volumes $\left(V_{0(t i s s u e)}^{e x p}\right.$ and $V_{0 f(\text { tissue })}$ in Table 2$)$ is observed (volume smaller than $3 \mu l$ ). This volume is smaller than the initial volume measurement accuracy and highlights the limited leakage at the beginning of the tests.

In the literature, the experimental data from aspiration measurements were used to estimate Young's moduli of silicones assuming a Neo-Hookean model [22]. A difference of about 30\% between inverse characterization (using the optical aspiration device LASTIC) and classical characterization of silicone materials with a similar range of elasticity was obtained. For the studied friction coefficients $(\mu=[0,1])$, errors of $[8.8,5.6] \%$ and $[6.6,4.1] \%$ in the val- 


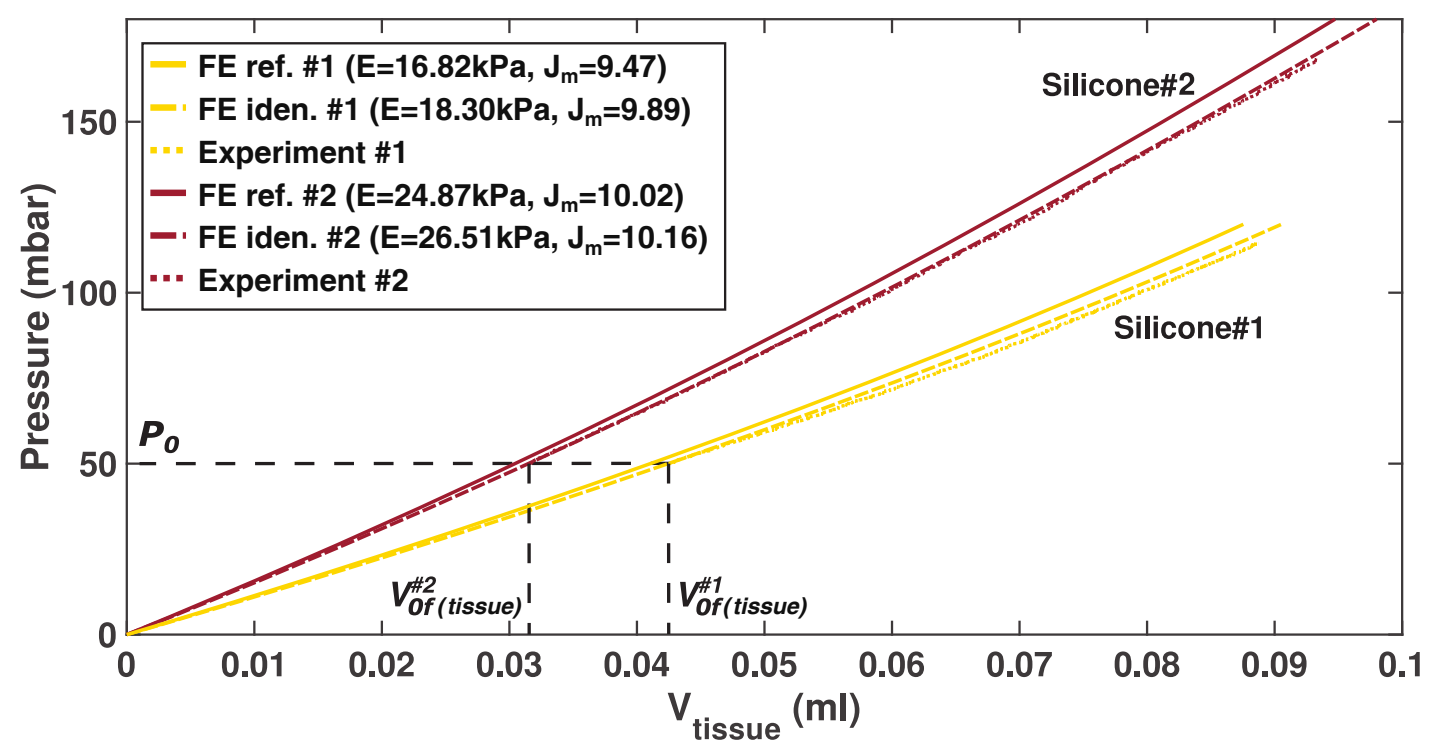

Fig. 8 Averages of the aspiration measurements and the corresponding FE simulation curves (with frictionless contact $\mu=0$ using the reference parameters obtained from classical measurements and the identified parameters from the inverse procedure (Table 1 and 2)) for Silicones \#1 and \#2.

ues of Young's moduli of Silicones \#1 and \#2 were estimated, respectively (Table 1).

The improvement of Young's modulus estimation in the volume-based aspiration device comparing to LASTIC is due to:

- continuous recording of the pressure data at a sampling frequency of $5 \mathrm{~Hz}$ with a precision of \pm 0.004 mbar using a digital manometer comparing to pressure measurement precision of \pm 6 mbar in [22].

- replacement of the apex height measurement by the aspirated volume measurement and thus avoidance of optical alignment errors.

- application of a direct inverse FE procedure versus the use of a library of pre-arranged FE simulations results in [22].

- use of a Gent model in this study versus the Neo-Hookean model used by Luboz et al. [22]. The Gent constitutive model seems indeed to properly model the used silicone materials(Fig. 7). In fact, the Neo-Hookean model can provide a softening effect at large strains. On the contrary, using a 
Gent model allows to define a stiffening effect controlled by the parameter $J_{m}$. Such a stiffening effect is often observed in biological soft tissues.

As observed in the previous study [22], Young's moduli were overestimated. Part of this error was induced by the chosen friction coefficient in the FE model (Table 1). This error was not totally induced by this parameter as the identified moduli remain overestimated even for a friction of $\mu=1$ (assuming the actual friction coefficient belongs to the range $\mu=[0,1])$.

The remaining error may partly be attributed to the experimentally residual and unknown vertical load applied to the aspiration head due to the head and tube weight (Fig 1). A sensitivity analysis would be required to assess the effect of each parameter. This will be performed in further work.

In this work, the value of $V_{0(\text { tissue })}^{e x p}$ is considered unknown during the inverse identification process. This choice adds a degree of freedom during the identification and may affect the identified model parameters. In fact, the data about the tissue behavior while reaching point $\left(V_{0(\text { tissue })}^{\text {exp }}, P_{0}\right)$ would be of first interest when performing inverse identification on biological soft tissues: the material may rapidly "stiffen" at low strain and at pressures lower than $P_{0}$. Unfortunately, soft materials behaviors at small loadings are extremely difficult to measure experimentally, especially in-situ and in-vivo; the reference state of soft biological materials will remain badly defined due to the presence of internal residual stress or unknown initially applied loads. Localizing the zero both in strain and stress for such a soft material is an arduous and interesting problem that was out of the scope of this paper.

In this study, the difference between the experimental and identified initial volumes $\left(V_{0(\text { tissue })}^{\text {exp }}\right.$ and $\left.V_{0 f(t i s s u e)}\right)$ is lower than $6 \%$. This difference is small and accounts both for the absence of leakage during measurement, and for the 
model ability to predict the unknown material behavior for pressure smaller than $P_{0}$.

\subsection{Qualitative comparison of experimental data}

Assuming a constitutive model to properly simulate the studied material behavior (hyperelastic, poroelastic or viscoelastic models in the case of timedependent behavior) is an arduous and complex task when performing an inverse identification on biological tissues. Using aspiration tests and in the absence of leakage, significant differences between experimental and identified

initial volumes ( $V_{0(t i s s u e)}^{e x p}$ and $V_{0 f(t i s s u e)}$, respectively) would lead to question the chosen constitutive model ability to properly describe the material behavior for low strain.

It is thus believed by the authors that analyzing the experimental data without assuming a specific behavior model partially circumvents this issue. This is the reason why a simple ratio of the two silicones' results is provided in this section. In addition, performing such an analysis highlights the method ability to provide contrast between different mechanical local behaviors: this feature will enable the creation of contrast maps on the surface of mechanical heterogeneous materials as frequently met during in vivo and in situ measurements. Such analyzes were very preliminary investigated by Schiavone et al. [20], where aspiration tests on different locations of the brain surface allowed to identify the position of a stiffer region corresponding to a surface tumor.

The loading ratios for the two silicones were calculated for each characterization method: 

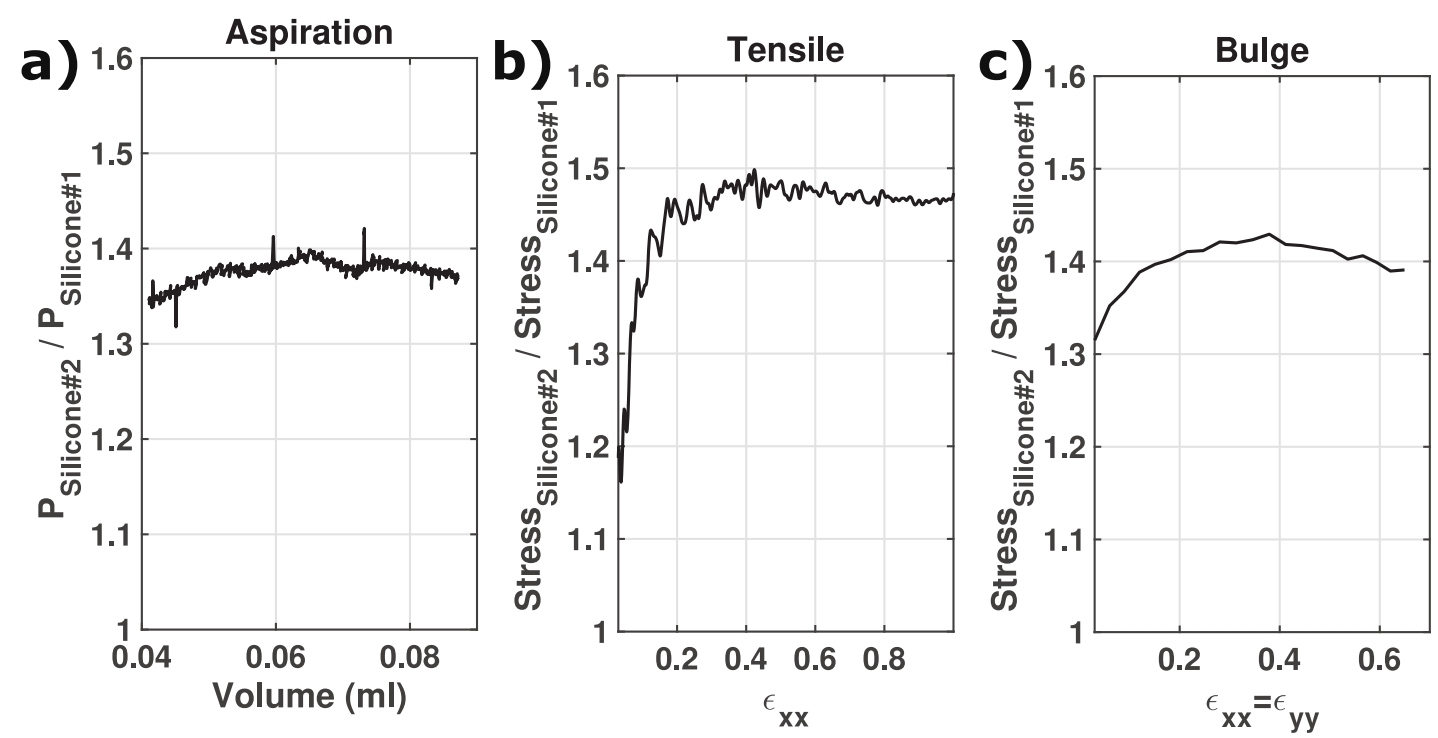

Fig. 9 Ratios of averaged experimental data for a) aspiration tests, b) tensile tests and c) bulge tests.

- by dividing pressures of Silicones\#2 to \#1 at the same volume for aspiration tests (Von Mises strain at the pole of the aspirated volume was in the range $[0.19,0.41])$,

- by dividing stresses of Silicones\#2 to \#1 at the same strain for the tensile and bulge tests, respectively.

The loading ratios are compared in Fig. 9. The ratios for all the aspiration, tensile and bulge tests are of similar values. The observed contrasts between the mechanical behaviors of the two silicones are thus similar, even if local stress states are very different from one test to another (triaxial (aspiration), biaxial (bulge), uniaxial (tensile)). These results indicate a similar ability of the tested mechanical characterization methods to highlight the contrast between different mechanical behaviors. Aspiration data can thus be used to highlight mechanical behavior contrasts between different materials zones without requiring a time-consuming inverse identification step.

More investigations on heterogeneous and anisotropic materials will be performed in the future works. 


\subsection{User Recommendations}

To use the volume-based aspiration method, a user should take the following considerations into account:

- to reduce experimentally induced bias, the absence of leakage between the tissue and the measurement probe should be checked before performing the tests. To ensure this, the initial negative pressure $P_{0}$ stability versus time should be checked. Ultrasound gel could be used between the suction probe and the studied material to improve leakage prevention.

- in the aspiration tests, the friction between the aspiration probe and the studied material is unknown. Adding Ultrasound gel between the suction probe and the studied material would reduce the contact friction during the experiments, so as to diminish the range choice for $\mu$ in the simulations.

- according to previous results [25], using a syringe with a smaller diameter for the measurements increases reproducibility of the results and decreases the measurements errors. In this work, the use of a syringe with a diameter of $4.7 \mathrm{~mm}$ was possible thanks to the setup presented in Fig. 1.

- the use of various loading steps provides a tool to check the measurements reproducibility (Fig. 2).

- the use of a special suction probe holder would be advisable in order to avoid applying external load on the suction probe.

\section{Conclusion}

A volume-based aspiration method for in-vivo characterization of soft tissues was evaluated on silicone materials. The ability of the method to discriminate two slightly different silicones was assessed. The aspiration test was repeated nine times on each material. The percentages of STD according to average vol- 
ume measurements of $2.63 \%$ and $2.53 \%$ were obtained for the two materials. The method will thus be able to discriminate aspiration behavior differences of $2 \times \mathrm{STD}=5 \%$. Additionally, the measured pressure ratio of the aspiration tests for the two materials is similar to the stress ratios obtained with classical characterization tests. A relative discrimination is thus easy and relative mechanical behavior mapping of soft tissues (organ or skin) is possible without requiring an inverse procedure.

The mechanical parameters of the Gent model were identified either on the classical or the aspiration tests using a direct and FE updating method, respectively. Young's moduli similar to the classical tests with about $7 \%$ maximum overestimation for the two silicones were identified. The errors are about 4 times lower than the previous studies based on optical aspiration measurements. These results indicate an improvement of the materials identification accuracy using the new device compared to the previous aspiration devices.

According to the presented results, the volume-based method can thus be used for (1) in-vivo and in-situ mapping without the inverse procedure, and (2) identification of the mechanical properties of various soft isotropic homogeneous materials. Further studies will be performed to extend the method to anisotropic and heterogeneous materials.

Acknowledgements This work has been started thanks to the CNRS (INS2I) PEPS "Young researcher" in 2015.

\section{References}

1. Schwenninger D, Schumann S, Guttmann J (2011) In vivo characterization of mechanical tissue properties of internal organs using endoscopic microscopy and inverse finite element analysis. J Biomech 44:487-493.

2. Payan Y, Ohayon J (2017) Biomechanics of Living Organs: Hyperelastic constitutive laws for finite element modeling, Elsevier, Academic Press Series in Biomedical Engineering. 
3. Budday S, Sommer G, Birkl C, Langkammer C, Haybaeck J, Kohnert J, Bauer M, Paulsen F, Steinmann P, Kuhl E, Holzapfel GA (2017) Mechanical characterization of human brain tissue. Acta Biomater 48:319-340.

4. Holzapfel GA, Ogden RW (2010) Constitutive modelling of arteries. P Roy Soc A-Math Phy 466:1551-1597.

5. Hollenstein M, Jabareen M, Breitenstein S, Riener MO, Clavien PA, Bajka M, Mazza E (2009) Intraoperative mechanical characterization of human liver. Proc Appl Math Mech 9:83-86.

6. Carter FJ, Frank TG, Davies PJ, McLean D, Cuschieri A (2001) Measurements and modelling of the compliance of human and porcine organs. Med Image Anal 5:231-236.

7. Samur E, Sedef M, Basdogan C, Avtan L, Duzgun O (2007) A robotic indenter for minimally invasive measurement and characterization of soft tissue response. Med Image Anal 11:361-373.

8. Yao W, Yoshida K, Fernandez M, Vink J, Wapner RJ, Ananth CV, Oyen ML, Myers KM (2014) Measuring the compressive viscoelastic mechanical properties of human cervical tissue using indentation. J Mech Behav Biomed 34:18-36.

9. Brown JD, Rosen J, Kim YS, Chang L, Sinanan MN, Hannaford B (2003) In-vivo and in-situ compressive properties of porcine abdominal soft tissues. St Heal T 94:26-32.

10. Agache PG, Monneur C, Leveque JL, Rigal JD (1980) Mechanical properties and Young's modulus of human skin in vivo. Arch Dermatol Res 269:221-232.

11. Diridollou S, Patat F, Gens F, Vaillant L, Black D, Lagarde JM, Gall Y, Berson M (2000) In vivo model of the mechanical properties of the human skin under suction. Skin Res Technol 6:214-221.

12. Badir S, Mazza E, Bajka M (2016) Objective assessment of cervical stiffness after administration of misoprostol for intrauterine contraceptive insertion. Ultrasound international open 2:63-67.

13. Vuskovic V (2001) Device for in-vivo measurement of mechanical properties of internal human soft tissues. Dissertation, Swiss Federal Institute of Technology Zurich.

14. Hendriks FM, Brokken D, Oomens CWJ, Bader DL, Baaijens FPT (2006) The relative contributions of different skin layers to the mechanical behavior of human skin in vivo using suction experiments. Med Eng Phys 28:259-266.

15. Badir S, Bajka M, Mazza E (2013) A novel procedure for the mechanical characterization of the uterine cervix during pregnancy. J Mech Behav Biomed 27:143-153.

16. Nava A, Mazza E, Furrer M, Villiger P, Reinhart WH (2008) In vivo mechanical characterization of human liver. Med Image Anal 12:203-206. 
17. Luboz V, Promayon E, Payan Y (2014) Linear elastic properties of the facial soft tissues using an aspiration device: towards patient specific characterization. Ann Biomed Eng 42:2369-2378.

18. Kauer M, Vuskovic V, Dual J, Szekely G, Bajka M (2002) Inverse finite element characterization of soft tissues. Med Image Anal 6:275-287.

19. Schiavone P, Boudou T, Promayon E, Perrier P, Payan Y (2008) A light sterilizable pipette device for the in vivo estimation of human soft tissues constitutive laws. Proc. 30th Annual Int. IEEE EMBS Conf., Canada, British Columbia, Vancouver, pp. 42984301.

20. Schiavone P, Chassat F, Boudou T, Promayon E, Valdivia F, Payan Y (2009) In vivo measurement of human brain elasticity using a light aspiration device. Med Image Anal 13:673-678.

21. Schiavone P, Promayon E, Payan Y (2010) LASTIC: a Light Apiration device for in vivo Soft TIssue Characterization. Proc. 5th Int. Symp. Biomedical Simulation ISBMS, Series: lecture notes in computer science, USA, pp 1-10.

22. Luboz V, Promayon E, Chagnon G, Alonso T, Favier D, Barthod C, Payan Y (2012) Validation of a light aspiration device for in vivo soft tissue characterization (LASTIC). In Payan Y (ed) Soft tissue biomechanical modeling for computer assisted surgery. Springer. pp 243-256.

23. Hollenstein M, Bugnard G, Joos R, Kropf S, Villiger P, Mazza E (2013) Towards laparoscopic tissue aspiration. Med Image Anal 17:1037-1045.

24. Weickenmeier J, Jabareen M, Mazza E (2015) Suction based mechanical characterization of superficial facial soft tissues. J Biomech 48:4279-4286.

25. Elahi SA, Connesson N, Payan Y (2018) Disposable system for in-vivo mechanical characterization of soft tissues based on volume measurement, J Mech Med Biol 18:1850037(17 pages).

26. Machado G, Stricher A, Chagnon G, Favier D (2017) Mechanical behavior of architectured photosensitive silicone membranes: Experimental data and numerical analysis. Mech Adv Mater Struc 24:524-533.

27. Hill R (1950) A theory of the plastic bulging of a metal diaphragm by lateral pressure. Philos Mag 41:1133-1142.

28. Franceschini G, Bigoni D, Regitnig P, Holzapfel GA (2006) Brain tissue deforms similarly to filled elastomers and follows consolidation theory. J Mech Phys Solids 54:25922620 .

29. Gent AN (1996) A new constitutive relation for rubber. Rubber Chem Technol 69:59-61. 
30. Chagnon G, Marckmann G, Verron E (2004) A comparison of the Hart-Smith model with Arruda-Boyce and Gent formulations for rubber elasticity. Rubber Chem Technol $77: 724-735$.

31. Marckmann G, Verron E (2006) Comparison of hyperelastic models for rubber-like materials. Rubber Chem Technol 79:853--858.

32. Nelder JA, Mead R, A simplex method for function minimization (1965) Comput J $7: 308-313$.

33. Rey T, Chagnon G, Le Cam JB, Favier D (2013) Influence of the temperature on the mechanical behaviour of filled and unfilled silicone rubbers. Polym Test 32:492-501. 